\title{
Use of Charcoal Haemoperfusion in the Management of Severely Poisoned Patients
}

\author{
J. A. VALE, A. J. REES, B. WIDDOP, R. GOULDING
}

British Medical fournal, 1975, 1, 5-9

\section{Summary}

The clinical use of uncoated charcoal haemoperfusion systems, despite their efficacy, has hitherto been prevented by the occurrence of a number of adverse effects including charcoal embolism and marked thrombocytopenia. Charcoal coated with a synthetic hydrogel overcomes many of the disadvantages associated with the use of uncoated material in that there is a much reduced thrombocytopenia and no evidence of charcoal embolism. Six patients, severely poisoned as a result of overdoses of either a barbiturate or glutethimide, were haemoperfused using such a system. Four made complete recoveries, and the two patients who died had both suffered cardiorespiratory arrests before perfusion. In contrast to haemodialysis charcoal haemoperfusion is simple to initiate, less expensive in terms of manpower and equipment, and gives superior clearance data for all barbiturates and glutethimide. We believe that this technique may have a significant role to play in the management of the severely poisoned patient.

\section{Introduction}

The overall mortality from acute poisoning among the 100000 patients admitted each year to hospitals in England and Wales is now less than $1 \%$ (Goulding, 1974), and most of the patients recover physically without any special treatment. The remainder are treated supportively along the lines first advocated by Clemmesen and Nilsson (1961). While there can be no substitute for such good medical and nursing care there is, nevertheless, a small group of very severely poisoned patients for whom some active means of removing the drug would be

Guy's Hospital, London SEi 9RT

J. A. VALE, M.B., M.R.C.P., Registrar in Clinical Toxicology A. J. REES, M.B., M.R.C.P., Renal Registrar

B. WIDDOP, B.SC., PH.D., Principal Biochemist, Poisons Unit R. GOULDING, M.D., F.R.C.P., Director, Poisons Unit advantageous in addition to the basic supportive measures. Efficient methods to promote, for example, the excretion of central nervous system depressant drugs might not only reduce the length of coma, and as a result the number and severity of the complications occurring in such patients, but could also reduce the mortality (Vale, 1974).

Three methods are currently available for this purposeforced diuresis, peritoneal dialysis, and haemodialysis. Forced alkaline diuresis is indicated only for phenobarbitone, barbitone, and salicylate poisoning; forced acid diuresis is indicated only in severe acute amphetamine and quinine poisoning; and peritoneal dialysis seems to have an established place only in the management of lithium overdose. Haemodialysis, moreover, has not so far proved convincing in the care of patients with overdoses of the short- and medium-acting barbiturates and the non-barbiturate hypnotics, which are responsible for many of the serious and fatal poisonings in this country.

A further method has recently become available for clinical use. Haemoperfusion, the passage of blood through various adsorbent materials, including charcoal, combines efficacy with relative simplicity, but its use has hitherto been restricted because of complications including embolism, marked thrombocytopenia, leucopenia, fibrinogen loss, and pyrexial reactions. Many of these side effects have now been overcome by coating the charcoal (Chang et al., 1973). In view of the encouraging results of Andrade et al. (1971), Willson et al. (1973, and our own in-vitro and in-vivo work in dogs (Widdop et al., 1975), we have investigated the ability of a specially developed acrylic hydrogel coated charcoal haemoperfusion system (Smith and Nephew Research Ltd) to remove the drug from six severely poisoned patients.

\section{Haemoperfusion Technique}

The haemoperfusion circuit is shown diagrammatically in fig. 1. The charcoal columns are specially designed and presterilized by Smith and Nephew Research and are not reusable. Each column contains about $300 \mathrm{~g}$ of 5- to 10-mesh coconut shell charcoal (Sutcliffe and Speakman, Wigan, code no. 610). The charcoal is thoroughly washed by fluidized bed processes to remove particulate matter and soluble impurities that may be leached by blood. After drying the charcoal is coated with an 
acrylic hydrogel to a thickness of $5 \mu \mathrm{m}$ ( $2 \%$ by weight) and packed into a double conically-shaped column with $600 \mu \mathrm{m}$ meshes at each end. The effluent discharge from the column satisfies the British Pharmacopoeia specification for particulate matter in infusion fluids. The different appearances under the electron microscope of coated and uncoated charcoal are shown in fig. 2.

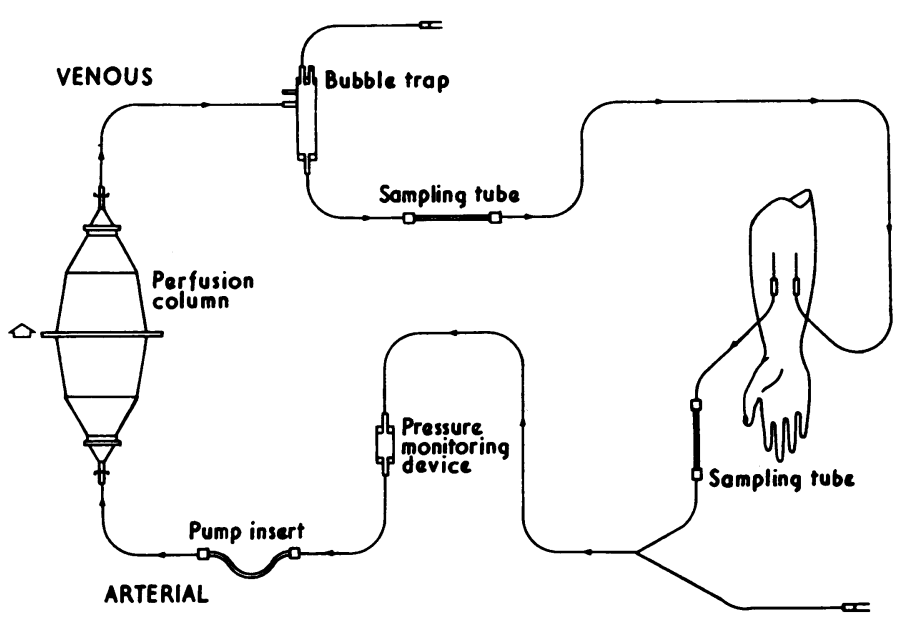

FIG. 1-Diagram of haemoperfusion circuit.

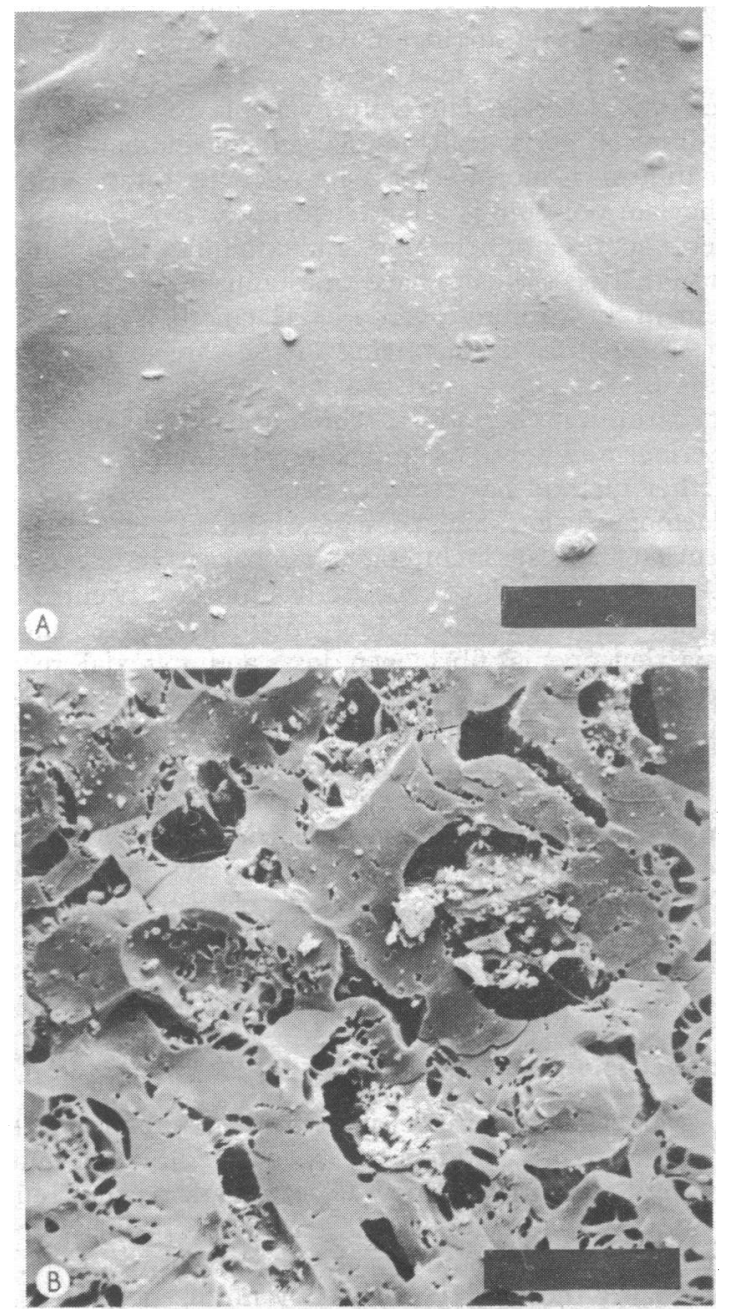

FIG. 2-Electron microscope appearances ( $x$ 867) of (a) coated and (b) uncoated charcoal.
Specially manufactured and shortened haemodialysis lines (Avon Medicals Ltd) connect the arteriovenous shunt to the haemoperfusion column. Before use two litres of sodium chloride $(0.9 \% \mathrm{w} / \mathrm{v})$ is run through the column and the circuit is then left primed with heparinized saline containing heparin $1 \mathrm{U} / \mathrm{ml}$. A Watson-Marlow roller pump is included in the arterial line to produce an upward flow through the column of about $200 \mathrm{ml} / \mathrm{min}$.

The following heparinization regimen was used: a bolus of 5000 units heparin was injected into the arterial line on beginning haemoperfusion; heparinization was continued by adjusting the rate of the heparin infusion $(1000 \mathrm{U} / \mathrm{ml}, 0.9 \% \mathrm{w} / \mathrm{v}$ sodium chloride) so that a plasma heparin concentration of 2.5-5 U/ml plasma was achieved. Alternatively, the Lee-White clotting time was maintained within the range of 30-60 minutes. A rate of infusion of one drop in five seconds was usually the maximum required and was controlled by the use of a Watson-Marlow roller pump; at the end of perfusion the blood in the extracorporeal circuit (about $450 \mathrm{ml}$ ) was returned to the patient by washing through the column with $5 \%$ dextrose.

As an additional safety measure a monitor-for example F.M. Type C, Dylade Co, Runcorn-may be included in the circuit to alarm and stop the blood pump if the bubble trap level drops precipitately or if there is a sudden decrease of pressure in the arterial line fistula.

\section{Patients}

To be included in this preliminary study patients had to have (a) severe clinical intoxication-for example, deep coma, hypotension, hypothermia, or hypoventilation; (b) progressive clinical deterioration despite good supportive management; $(c)$ prolonged coma with complications such as pneumonia and underlying chronic respiratory disease; and $(d)$ very high plasma drug levels.

Of the six patients two had taken overdoses of phenobarbitone, two of butobarbitone, one of pentobarbitone, and one of glutethimide. All patients were treated with full supportive measures to maintain respiration and blood pressure and were also haemoperfused.

Case 1.-This 56-year-old woman was found unconscious at home by her husband. It later transpired that the previous day she had obtained a prescription for butobarbitone from her general practitioner and had bought a bottle of sherry. These she consumed. On admission to hospital she was deeply unconscious (grade 4), hypotensive (blood pressure 40/? $\mathrm{mm} \mathrm{Hg}$ ), hypothermic $\left(31^{\circ} \mathrm{C}\right)$, and required mechanical ventilation. Resuscitative measures were begun while arrangements were made to transfer the patient to Guy's Hospital for haemoperfusion. The preperfusion butobarbitone level was $320 \mu \mathrm{mol} / 1$. $(6.8 \mathrm{mg} / 100 \mathrm{ml})$. One hour after beginning charcoal perfusion the patient's condition had improved sufficiently for her to be taken off the ventilator. At the end of perfusion, three and a half hours later, she was clinically normal except that the level of consciousness was grade 1 . A drug clearance of $120 \mathrm{ml} / \mathrm{min}$ was achieved and this gave a calculated removal of $1007 \mathrm{mg}$ of butobarbitone during the four and a half hours of perfusion compared with $87 \mathrm{mg}$ in the urine of a 24-hour period. The platelet counts before and at the end of perfusion were

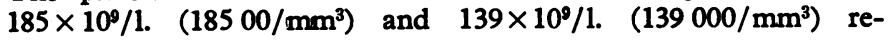
spectively.

Case 2.-A nurse of 23 years was found unconscious at home by her husband. An empty bottle of phenobarbitone was found beside her. On admission to hospital she had evidence of pneumonia and was deeply unconscious (grade 4), hypotensive (90/60 $\mathrm{mm} \mathrm{Hg}$ ), hypothermic $\left(26^{\circ} \mathrm{C}\right)$, and required ventilation. A forced alkaline diuresis was begun and 22 hours after the overdose had been taken the patient was transferred to Guy's Hospital for haemoperfusion. Toxicological analysis had indicated that the level 
immediately before perfusion was $1121 \mu \mathrm{mol} / 1$. ( $26 \mathrm{mg} / 100 \mathrm{ml}$ ). Forty-five minutes after beginning haemoperfusion the patient was taken off the ventilator, but perfusion was continued for six hours altogether, by which time the level of consciousness had improved to grade 2. A drug clearance of $120 \mathrm{ml} / \mathrm{min}$ was achieved with a calculated removal of $5472 \mathrm{mg}$ phenobarbitone during perfusion, compared with $1806 \mathrm{mg}$ excreted in the urine over 36 hours. The platelet counts before and at the end of perfusion were $130 \times 10^{9} / 1$. $\left(130000 / \mathrm{min}^{3}\right)$ and $62 \times 10^{9} / 1 .\left(62000 / \mathrm{mm}^{3}\right)$ respectively.

Case 3--A 31-year-old medical practitioner was found unconscious in his room 34 hours after taking 167 phenobarbitone tablets and half a bottle of whisky. When transferred to an intensive care unit he was deeply comatose (grade 4), hypotensive $(70 / 30 \mathrm{~mm} \mathrm{Hg})$, anoxic $\left(\mathrm{Po}_{2} 4.4 \mathrm{kPa}(33 \mathrm{~mm} \mathrm{Hg})\right)$, and had a leftsided pneumonia. The patient was intubated, a Mary Catterall (M.C.) mask was placed over the end of the endotracheal tube (oxygen flow $15 \mathrm{l} . / \mathrm{min}$ initially), and a forced alkaline diuresis was begun while arrangements were made to transfer the patient to Guy's Hospital. The phenobarbitone level was then found to be $621 \mu \mathrm{mol} / 1$. (14.4 mg/100 ml). Haemoperfusion was continued for seven hours, by which time the patient's level of consciousness had improved to grade 2, he no longer required an endotracheal tube, and he was normotensive and well oxygenated. A drug clearance of $90 \mathrm{ml} / \mathrm{min}$ was achieved, with a calculated removal of $3734 \mathrm{mg}$ phenobarbitone during perfusion, while $296 \mathrm{mg}$ was excreted in the urine over the first two days in hospital. The platelet counts before and at the end of perfusion were $124 \times 10^{9} / 1$ $\left(124000 / \mathrm{mm}^{3}\right)$ and $103 \times 10^{9} / 1 .\left(103000 / \mathrm{mm}^{3}\right)$ respectively.

Case 4.-A man of 31 years was found unconscious with minor contusions over the forehead. Because of the evidence of trauma he was initially treated in hospital as a head injury. A few hours later his level of consciousness deteriorated (grade 4) and he required ventilation. Pneumonia was detected both clinically and radiologically. Toxicological analysis showed a glutethimide level of $360 \mu \mathrm{mol} / 1$. $(7.8 \mathrm{mg} / 100 \mathrm{ml})$ and the presence of methadone. (It was later learnt that the patient was a methadone addict.) Four hours after beginning haemoperfusion it was possible to take the patient off the ventilator and two hours later when perfusion was discontinued the patient's level of consciousness had improved to grade 2. A drug clearance of $125 \mathrm{ml} / \mathrm{min}$ was achieved, with a calculated removal of $1220 \mathrm{mg}$ glutethimide by haemoperfusion whereas only $71 \mathrm{mg}$ appeared in the urine over the first two days after admission. The platelet counts before and at the end of perfusion were $107 \times 10^{9} / 1$. $\left(107000 / \mathrm{mm}^{3}\right) 64 \times 10^{9} / 1 .\left(64000 / \mathrm{mm}^{3}\right)$ respectively.

Case 5.-A 56-year-old medical practitioner who had been depressed for some months took a large number of pentobarbitone capsules and alcohol. One hour after the ingestion of this overdose and before admission to hospital the patient was found unconscious and shortly afterwards suffered a cardiorespiratory arrest but was successfully resuscitated by one of his partners. On admission he was deeply comatose (grade 4 ), hypothermic $\left(33^{\circ} \mathrm{C}\right.$ ), hypotensive $(65 /$ ? $\mathrm{mm} \mathrm{Hg})$, and required ventilation. Toxicological analysis indicated a pentobarbitone level of $249 \mu \mathrm{mol} / 1$. $(5.6$ $\mathrm{mg} / 100 \mathrm{ml}$ ) and an ethanol level of $37.9 \mathrm{mmol} / 1$. $(175 \mathrm{mg} / 100$ $\mathrm{ml}$ ). As the patient's condition was unchanged 24 hours after admission despite very active resuscitative and supportive measures he was transferred to Guy's Hospital for haemoperfusion though it was suspected that irreversible cerebral damage secondary to the arrest had already occurred. The patient was perfused for eight hours but unfortunately for the last hour of perfusion the flow was reduced because of a greatly impaired venous return. A drug clearance of $50 \mathrm{ml} / \mathrm{min}$ was, however, achieved despite the patient's general deterioration during the time of perfusion. Subsequently, he suffered another cardiac arrest after the development of partial and then complete heart block and could not be resuscitated. During the period of perfusion $1728 \mathrm{mg}$ of pentobarbitone was removed. Platelet counts before and at the end of perfusion were $84 \times 10^{9} / 1 .\left(84000 / \mathrm{mm}^{3}\right)$ and $38 \times 10^{9} / 1$. $(38000 /$ $\mathrm{mm}^{3}$ ) respectively. Necropsy indicated that the patient had bled from an attempted cannulation of the vein for the insertion of a central venous pressure line and this was probably responsible for the poor venous return. At necropsy, however, there was evidence of cerebral anoxic damage to account for death.

Case 6.-A 62-year-old widower was admitted to hospital having been found unconscious at home by his daughter. On admission he was deeply comatose (grade 4), hypotensive $(60 / 40 \mathrm{~mm} \mathrm{Hg}$ ), and required ventilation. Subsequently he developed a pyrexia $\left(39.5^{\circ} \mathrm{C}\right)$ which was thought to be due to a hypostatic pneumonia. Despite intensive therapy and supportive measures the patient suffered a cardiopulmonary arrest (asystole) but was resuscitated. Initial toxicological analysis indicated a butobarbitone level of $188 \mu \mathrm{mol} / 1$. ( $4 \mathrm{mg} / 100 \mathrm{ml}$ ) and the presence of small amounts of dihydrocodeine and diazepam. Two days after the overdose had been taken it was decided to transfer the patient to Guy's Hospital for haemoperfusion to increase the elimination of barbiturate so that it might be known with certainty that his poor general condition was directly due to the toxic effects of the drug. Haemoperfusion was begun, but though supportive measures were continued the patient's condition still deteriorated and he died within 12 hours of transfer. Despite the poor flow rate $(50-75 \mathrm{ml} / \mathrm{min})$ a mean drug clearance of $50 \mathrm{ml} / \mathrm{min}$ was achieved over the four hours of perfusion, and $375 \mathrm{mg}$ of butobarbitone were calculated to have been removed in this way. Platelet counts before and at the end of perfusion were $55 \times 10^{9} / 1 .\left(55000 / \mathrm{mm}^{3}\right)$ and $32 \times 10^{9} / 1$. $\left(32000 / \mathrm{mm}^{3}\right)$ respectively. At necropsy there were signs of cerebral anoxic damage.

\section{Biochemical and Haematological Tests}

Blood was taken both before and after and sometimes during perfusion for estimation of electrolytes, urea, calcium, phosphate, alkaline phosphate, glucose, proteins, bilirubin, cholesterol, aspartate and alanine aminotransferases, urate, creatinine, fatty acids, fat soluble vitamins, blood picture, coagulation profile, and drug levels. In addition, samples were taken during perfusion for estimation of drug levels (pre- and post-column), platelet, leucocyte, and heparin levels. The biochemical and haematological estimations were carried out by routine techniques: heparin concentrations were determined by a modification of the method of Pitney (1968) and drug levels were measured by a specific gas liquid chromatographic technique (Flanagan and Withers, 1972).

\section{Results}

\section{CLINICAL RESPONSE}

Four of the six patients made complete recoveries, including one doctor and one nurse who both returned to work. Haemoperfusion was continued for between four and a half and eight hours, except in case 6 in which perfusion had to be discontinued prematurely because flow through the column could not be maintained as a result of profound arterial hypotension. Not only were the drug clearances impressive but also the often rapid improvement in the level of consciousness was particularly striking. This sometimes occurred even though the plasma drug level was still fairly high, and it might be explained in terms of compartment shift. Three of the four patients who recovered required ventilation initially, but it was possible to discontinue this 40 minutes (case 2), one hour (case 1), and four hours (case 4) after beginning perfusion. Neither of the two patients who died could be taken off the ventilator despite considerable reduction in their plasma drug levels. This presumably reflected the irreversible anoxic damage as a result of the cardiorespiratory arrest suffered by both of them.

Except for the modest reduction in platelet count in each patient and the bleed in one patient (case 5) no complications were seen in the six perfused patients. In particular, there was no evidence of hypotension or drop in the central venous pressure when beginning perfusion or evidence of charcoal embolism.

The two patients who died were perfused for essentially 
TABLE I-Comparison of Presentation, Management and Outcome in Cases 2 and 7

\begin{tabular}{|c|c|c|c|c|c|c|c|c|c|c|c|c|}
\hline & & \multirow{2}{*}{$\begin{array}{l}\text { Age } \\
\text { Sex, } \\
\text { and } \\
\text { Marital } \\
\text { Status }\end{array}$} & \multirow{2}{*}{$\begin{array}{c}\text { Admitted } \\
\text { to Guy's } \\
\text { Hospital } \\
\text { (Time (h) after } \\
\text { Overdose) }\end{array}$} & \multirow{2}{*}{$\begin{array}{c}\text { Initial } \\
\text { Phenobarbitone } \\
\text { Level } \\
(\mu \mathrm{mol} / 1 .)\end{array}$} & \multirow{2}{*}{$\begin{array}{l}\text { Clinical } \\
\text { Features }\end{array}$} & \multicolumn{2}{|c|}{$\begin{array}{l}\text { Length of } \\
\text { Treatment }\end{array}$} & \multicolumn{3}{|c|}{ Amount of Drug Removed } & \multirow{2}{*}{$\begin{array}{c}\text { Approx. } \\
\text { No. of } \\
\text { Tablets } \\
\text { Removed }\end{array}$} & \multirow{2}{*}{ Outcome } \\
\hline & & & & & & F.A.D. & $\begin{array}{l}\text { Haemo- } \\
\text { perfusion }\end{array}$ & URINE & $\begin{array}{l}\text { Haemo- } \\
\text { perfusion }\end{array}$ & Total & & \\
\hline Case 2 & . & $\begin{array}{l}23 \mathrm{~F} . \\
\text { married } \\
27 \mathrm{~F} \text {. } \\
\text { married }\end{array}$ & 22 & 1578 & $\begin{array}{l}\text { Coma (grade 4), } \\
\text { hypotension, } \\
\text { hypothermia, } \\
\text { pneumonia } \\
\text { Coma (grade 4), } \\
\text { hypotension, } \\
\text { hypothermia }\end{array}$ & (50 litres) & $6 \mathrm{~h}$ & $\begin{array}{c}1806 \mathrm{mg} \\
(36 \mathrm{~h}) \\
\\
2378 \\
(4 \mathrm{~d})\end{array}$ & 5472 & 7278 & 240 & $\begin{array}{l}\text { Full recovery, } \\
\text { return to work } \\
\text { Died }\end{array}$ \\
\hline
\end{tabular}

F.A.D. $=$ Forced alkaline diuresis.

Conversion: SI to Traditional Units-Phenobarbitone: $1 \mu \mathrm{mol} / 1 \approx 0.0212 \mathrm{mg} / 100 \mathrm{ml}$.

diagnostic rather than therapeutic reasons. It was thought that if no improvement ensued after drug removal the patients were likely to have suffered irreversible cerebral damage secondary to anoxia. A decision could then be made as to whether to turn off the ventilator in hours rather than days. In fact the patient in case 5 suffered a further cardiorespiratory arrest after a short period of complete heart block and could not be resuscitated. No improvement in his condition was noted, however, despite the fact that the plasma pentobarbitone level had by then been reduced to $89 \mu \mathrm{mol} / \mathrm{l}$. $(2 \mathrm{mg} / 100 \mathrm{ml})$. The patient in case 6 was moribund on arrival; he was hypothermic, had an unrecordable blood pressure, was in acute renal failure, required ventilation, and manifested a variety of cardiac arrhythmias. Despite a reduction of the plasma butobarbitone level to $90 \mu \mathrm{mol} / 1$. $(1.9 \mathrm{mg} / 100 \mathrm{ml})$, the patient showed no signs of recovery.

In the light of our initial results we would not consider it ethically justifiable to place very severely poisoned patients in a non-haemoperfused control group. Nevertheless, we were able to observe a comparable patient who was energetically treated by conventional means. The similarity between this patient (case 7) and the patient in case 2 on admission was striking (table I) yet the outcome was so different. The plasma drug concentration profiles are shown in fig. 3. The nonhaemoperfused patient died four days after taking the overdose from the "shock-lung" syndrome.

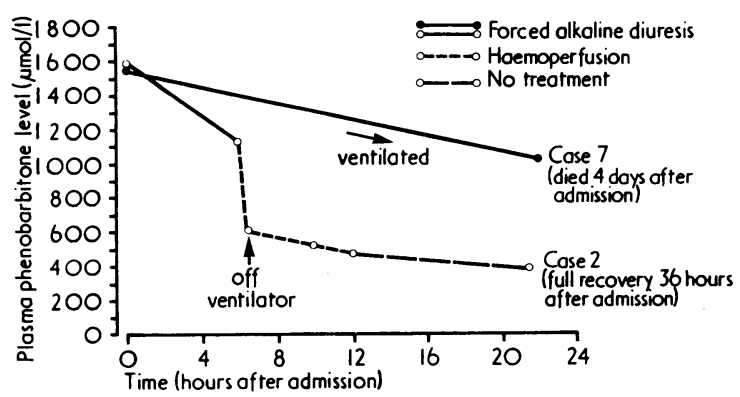

FIG. 3-Plasma drug concentration profiles of two patients with severe phenobarbitone poisoning, one (case 7) treated with forced alkaline diuresis and one (case 2) treated with with forced alkaline
haemoperfusion also.

Conversion: SI to Traditional Units-Phenobarbitone: $1 \mu \mathrm{mol} / 1 \approx 0.023 \mathrm{mg} / 100 \mathrm{ml}$.

\section{EFFECTS ON PLATELETS AND LEUCOCYTES}

In each of the four patients who recovered there was a fall in the platelet count, usually within 30 minutes of beginning haemoperfusion, which was followed by a spontaneous rise over the next two to three days to levels similar to those found initially. Two of the four patients had postperfusion platelet counts greater than those found initially. The two patients who died (cases 5 and 6) both had initial platelet counts below $100 \times 10 \%$. $\left(100000 / \mathrm{mm}^{3}\right)$ with a fall of $54 \%$ and $41 \%$ respec- tively in their platelet levels whereas the mean reduction in platelet levels between beginning haemoperfusion and discontinuing the procedure for the group as a whole was $38 \%$ (range 16-54\%). The highest percentage reduction occurred in the patient in case 5, who had bled from a failed subclavian vein cannulation. Except in this patient there was no evidence of bleeding or mucosal haemorrhages during or after haemoperfusion.

Within one hour of beginning haemoperfusion in case 4 a second column had to be introduced into the circuit because of clotting due to the use of a new heparinization schedule which proved inadequate. There was no further fall in platelet count after this, which confirmed our experience with animals that there is little platelet deposition on coated charcoal. The bubble trap is probably responsible for much of the platelet loss and we are currently investigating this with radioactive platelet labelling.

A slight fall in leucocyte levels was found on beginning haemoperfusion but this was usually followed by a moderate rebound so that by the end of perfusion the leucocyte level was higher than the preperfusion level.

\section{BIOCHEMICAL CHANGES}

Though many biochemical values were investigated during haemoperfusion there was no change in the arterial concentration of any of these with the exception that in case 5 there was a fall in the patient's plasma urate and cholesterol levels to $1.5 \mathrm{mmol} / \mathrm{l}$. $(2.5 \mathrm{mg} / 100 \mathrm{ml})$ and $2 \cdot 1 \mathrm{mmol} / 1 .(80 \mathrm{mg} / 100 \mathrm{ml})$ respectively. We found no fall in the plasma glucose level on beginning perfusion, in contrast to the findings reported by Gazzard et al. (1974). The fact that some of the patients were receiving glucose intravenously, however, may have partly masked this effect in our patients.

\section{Discussion}

The adsorbent action of charcoal has been known for many years. Andersen (1948), for example, showed its ability to adsorb barbiturates, and some would advocate its routine use as an oral antidote for ingested toxic substances (Holt and Holz, 1963; Corby et al., 1970). Yatzidis (1964 a, b; Yatzidis et al., 1965) was the first to describe the use of charcoal haemoperfusion for the removal of creatinine, urate, phenols, guanides, salicylates, barbiturates, and glutethimide. Dunea and Kolff (1965) observed a similar reduction in urate and creatinine levels, and Hagstam et al. (1966) and De Myttenaere et al. (1967) found satisfactory clearance rates for phenobarbitone and glutethimide. Unfortunately, the use of uncoated charcoal was complicated by a number of adverse effects such as charcoal embolism, marked thrombocytopenia and leucopenia, fibrinogen loss, and pyrogen reactions.

To overcome some of these disadvantages, Pallotta et al. (1960), Kissack et al. (1962), Nealon et al. (1966), and Rosenbaum et al. $(1962,1968)$ investigated the use of anion-exchange 
resins, but complications persisted. Rosenbaum et al. (1970, 1971) have successfully overcome some of these by using an uncharged resin, Amberlite XAD-2, in animals and patients. In dogs the value of XAD-2 haemoperfusion and its superiority over haemodialysis has been reported (Medd et al., 1973), but thrombocytopenia and leucopenia occurred and, also, pyrexial reactions are known to arise in man. This resin was also found later to have a limited drug saturation capacity (unpublished results).

Attempts were therefore made to eliminate the disadvantages of charcoal by coating it with cellulose acetate (Yatzidis, 1967; Rosenbaum, 1968), collodion, collodion and albumin, heparincomplexed collodion, nylon (Chang et al., 1967, 1968; Chang, 1969; Chang and Malave, 1970), glutaraldehyde cross-linked bovine albumin (Andrade et al., 1972), and polyhydroxyethyl methacrylate (polyHEMA), a synthetic hydrogel (Andrade et al., 1971).

The successful use of an acrylic hydrogel coated charcoal haemoperfusion system for the removal of paracetamol in pigs (Willson et al., 1973) and a variety of drugs in dogs (Widdop et al., 1975) and in the treatment of liver failure (Gazzard et al., 1974) has been described. Charcoal coated in this way overcomes many of the disadvantages associated with uncoated material without seriously reducing its absordtive ability.

There was some reduction in the platelet count in each of the six patients, being greatest in the two who died, but the thrombocytopenia which we observed was of a similar order to that seen in haemodialysis (Lawson et al., 1966; Lindsay et al., 1972) and less severe than that encountered in cardiac bypass operations (Barkhan, 1967). Furthermore, in the four patients who recovered the platelet count returned to normal over the two to three days after haemoperfusion. In addition, there was no evidence of charcoal embolism.

Our results show that charcoal haemoperfusion is a most efficient method for increasing the elimination of all types of barbiturates and glutethimide. This is confirmed by a comparison of the clearance data obtained from the use of various techniques which increase drug elimination (table II). Animal work (Widdop et al., 1975) suggests that haemoperfusion may also be the best method available for promoting the excretion of methaqualone, salicylates, ethchlorvynol, trichloroethanol, and meprobamate.

TABLE II-Comparison of Clearances ( $\mathrm{ml} / \mathrm{min}$ ) of Drugs with Different Techniques of Drug Elimination

\begin{tabular}{|c|c|c|c|c|}
\hline Drug & $\begin{array}{l}\text { Forced } \\
\text { Diuresis }\end{array}$ & $\begin{array}{c}\text { Peritoneal } \\
\text { Dialysis }\end{array}$ & Haemodialysis & $\begin{array}{l}\text { Charcoal } \\
\text { Haemoperfusion }\end{array}$ \\
\hline Short-acting barbiturate & 5 & 10 & 20 & $\begin{array}{l}120(\text { case } 1) \\
50(\text { case } 5) \dagger \\
50(\text { case } 6) \dagger\end{array}$ \\
\hline Long-acting barbiturate & $17^{*}$ & 10 & 60 & $\begin{array}{r}120(\text { case } 2) \\
90(\text { case } 3)\end{array}$ \\
\hline Glutethimide .. & 10 & 10 & 40 & 125 (case 4$)$ \\
\hline
\end{tabular}

*On alkaline diuresis.

*On alkaline diuresis.
$\dagger$ Patients had suffered a cardio-respiratory arrest before haemoperfusion.

We advocate the use of charcoal haemoperfusion in the following cases: in patients in whom there is evidence of severe clinical intoxication; in severely poisoned patients who fail to improve despite the use of supportive measures; in patients in prolonged coma with such complications as pneumonia and underlying chronic respiratory disease; and in patients who are deeply unconscious and have suffered a cardiorespiratory arrest of brief duration and require ventilation. In this condition the rapid elimination of the drug allows a diagnosis of cerebral damage and, therefore, a decision about future management can be made in hours rather than in days.

In conclusion, we believe that charcoal haemoperfusion-a technique that is both simpler and more effective than haemodialysis-may have a significant role to play in the management of the very severely poisoned patient.

ADDENDUM.-We have since haemoperfused a further seven patients who had taken overdoses of barbiturates, glutethimide, or methyl salicylate. All patients recovered, and equally impressive lung clearances were obtained.

We thank the physicians who referred patients to $\mathrm{Lis}$ and $\mathrm{Mr}$. M. Bewick, Professor I. McColl, and Mr. T. H. Harrison, who inserted some of the shunts. We are grateful to our colleagues in the haematology department, particularly Mr. T. Thomas who monitored the heparin levels; to the nursing staff of the Guy's Hospital intensive care and renal units, particularly Sister $\mathrm{K}$. Goodhart; and to the biochemists of the poisons unit who undertook the toxicological analyses. We are pleased to acknowledge the support of Smith and Nephew Research in supplying the charcoal columns.

\section{References}

Andersen, A. H. (1948). Acta Pharmacologica et Toxicologica, 4, 379 Andrade, J. D., et al. (1971). Transactions. American Society for Artificial Internal Organs, 17, 222.

Andrade, J. D., et al. (1972). Transactions. American Society for Artificial Internal Organs, 18, 473.

Barkhan, P. (1967). Guy's Hospital Reports, 116, 115.

Chang, T. M. S., Johnson, L. J., and Ransome, O. J. (1967). Canadian fournal of Physiology and Pharmacology, 45, 705.

Chang, T. M. S., et al. (1968). Transactions. American Society for Artificial Internal Organs, 14, 163.

Chang, T. M. S., et al. (1969). Canadian Fournal of Physiology and Pharmacology, 47, 1043

Chang, T. M. S., and Malave, N. (1970). Transactions. American Society for Artificial Internal Organs, 16, 141

Chang, T. M. S., et al. (1973). Canadian Medical Association fournal, 108, 429.

Clemmesen, C., and Nilsson, E. (1961). Clinical Pharmacology and Therapeutics, $2,220$.

Corby, D. G., Fiser, R. H., and Decker, W. J. (1970). Paediatric Clinics of North America, 17, 544

De Myttenaere, M. H., Maher, J. F., and Schreiner, G. E. (1967). Transactions. American Society for Artificial Internal Organs, 13, 190.

Dunea, G. and Kolff, W. J. (1965). Transactions. American Society for Artificial Internal Organs, 11, 178.

Flanagan, R. J., and Withers, G. (1972). Fournal of Clinical Pathology, 25, 899 .

Gazzard, B. G., et al. (1974). Lancet, 1, 1301.

Goulding, R. (1974). In Modern Trends in Toxicology, ed. E. Boyland, and R. Goulding. London, Butterworth

Hagstam, K. E., Larsson, L.-E., and Thysell, H. (1966). Acta Medica Scandinavica, 180, 593 .

Holt, L. E., and Holz, P. H. (1963). Fournal of Pediatrics, 63, 306.

Kissack, A. S., jun., Gliedman, M. L., and Karlson, K. E. (1962). Transactions. American Society for Artificial Internal Organs, 8, 219

Lawson, L. J., et al. (1966). Proceedings of the European Dialysis and Transplant Association, 2, 63.

Lindsay, R. M., et al. (1972). British Medical fournal, 4, 454.

Medd, R. K., et al. (1973). Archives of Toxicology, 31, 163.

Nealon, T. F., jun., et al. (1966). Fournal of the American Medical Association, $197,118$.

197, 118. Experimental Therapeutics, $128,318$.

Pitney, W. R. (1968). In Practical Haemotology, ed. J. V. Dacie and S. M. Lewis. 4th. edn. London, Churchill.

Rosenbaum, J. L., Onesti, G., and Brest, A. N. (1962). Fournal of the American Medical Association, 180, 762.

Rosenbaum, J. L., Ronquillo, E., and Argyres, S. N. (1968). Fournal Alber Einstein Medical Center, 16, 67.

Rosenbaum, J. L., et al. (1970). Transactions. American Society for Artificial Internal Organs, 16, 134.

Rosenbaum, J. L., et al. (1971). New England fournal of Medicine, 284, 874

Vale, J. A. In Wilful and Accidental Poisoning. In press.

Widdop, B., et al. (1975). To be published.

Willop, B., et al. (1975). To be published. Yatzidis, $\mathrm{H}$. (1964 a). Proceedings of the European Dialysis and Transplant

Yatzidis, H. (1964 b). Nephron, 1, 310.

Yatzidis, H., et al. (1965). Lancet, 2, 216

Yatzidis, H. (1967). In III International Congress of Nephrology, ed. G. E. Schreiner, vol. 2, p. 299. Basel, Karger. 